\title{
Assessment of human thyroid function using radioimmunoassay and enzyme-linked- immuno-sorbent-assay
}

\author{
Mohamed Elfadil Mohamed Gar-Elnabi ${ }^{a}$, Reham Mohd Taha ${ }^{a}$, Mohammed Ahmed Ali Omer ${ }^{a}$, $*$, Mohamed Farahna ${ }^{b}$, \\ Yahia M. Bushara ${ }^{\mathrm{c}, \mathrm{b}}$ \\ ${ }^{a}$ College of Medical Radiologic Science, Sudan University of Science and Technology, Khartoum, Sudan \\ ${ }^{b}$ Radiologic Technology Department, College of Applied Medical Science, Qassim University, Buraidah, Kingdom of Saudi \\ Arabia \\ ${ }^{c}$ Department of Anatomy Faculty of Medicine and Health sciences, Al-Neelain University, Khartoum, Sudan
}

\section{ARTICLE INFO}

ABSTRACT

\section{Article History \\ Received \\ $30 / 07 / 2013$ \\ Accepted \\ $07 / 10 / 2013$}

\section{* Correspondence to:}

Mohamed Elfadil Mohamed Gar-Elnabi

College of Medical Radiologic Science,

Sudan University of Science and Technology,

Khartoum, Sudan

e-mail: alkajam@gmail.com

\section{Keywords:}

Assessment

Enzyme-Linked-Immuno-Sorbent-Assay

Hormones

Human

Radioimmunoassay
Thyroid function has been evaluated using Radioimmunoassay (RIA) and enzyme-linked-immuno-sorbent-assay (ELISA) techniques as a comparative study to determine the accuracy, sensitivity and specificity in addition to correlation with body mass index (BMI). For triiodothyronine (T3) measured by RIA, relatively ELISA showed sensitivity, specificity and accuracy of $93.8 \%, 100 \%$ and $99.1 \%$ respectively and for thyroxin (T4), ELISA showed sensitivity, specificity and accuracy of $79.3 \%, 89.4 \%$ and $86.8 \%$ respectively. And for thyroid-stimulating hormone (TSH) ELISA showed a sensitivity, specificity and accuracy of $72.4 \%, 90.6 \%$ and $86 \%$ respectively and relative to RIA technique which is considered as standard goal. And for compensating the ELISA results to be same as RIA the following coefficient $0.72,6.8$ and 0.23 for T3, T4 and TSH respectively could be used. Also there is inverse linear relationship between the BMI and T3 and T4 using ELISA whereas the amount of T3 and T4 decreases by $0.006 \mathrm{nmol} / \mathrm{kg} / \mathrm{m} 2$ and $0.051 \mathrm{nmol} / \mathrm{kg} / \mathrm{m} 2$ respectively. But TSH shows a direct linear relationship with BMI where TSH slightly increased by $0.007 \mathrm{nmol} / \mathrm{kg} / \mathrm{m}^{2}$.

J. Exp.Clin.Med., 2013; 30:317-321

\section{Introduction}

Thyroid disease is one of the most common endocrine disorders (Roberts et al, 2007). The laboratory diagnosis and monitoring of thyroid diseases such as hypo and hyperthyroidism are based on serum thyroid-stimulating hormone (TSH) measurement along with serum hormones thyroxin (T4) and triiodothyronine (T3) (both free and total) (Sanchez et al., 1994). Such gland is under control of pituitary gland via TSH, which in turn stimulates thyroid gland to make thyroid hormone (Hoermann et al., 2010).

The primary function of the thyroid is a production of $\mathrm{T} 4$, $\mathrm{T} 3$, and calcitonin. Up to $80 \%$ of the T4 is converted to T3 by peripheral organs such as the liver, kidney and spleen. T3 is about ten times more active than T4. High or low TSH level is usually secondary to thyroid disease. In hyperthyroidism and thyrotoxicosis; the TSH levels are found to be low due to the negative feedback of the excess T3 and T4. In hypothy- roidism the levels of TSH are high due to diminish thyroid hormone and therefore absence of the negative feedback (Van Herle et al., 1982). i.e. the production of this hormone is not possible without stimulation from the TSH which in turn is also regulated by the hypothalamus's thyrotropin-releasing hormone. Thyroid function tests have been dependent on an indirect estimate of the serum total thyroxin (T4) concentration, using protein bound iodine (PBI) technique by $1950 \mathrm{~s}$ (Benotti and Benotti, 1963); however since 1970s to recently there are many applied techniques such as: Radioimmunoassay (RIA) (Baloch et al, 2003), immunometric assay (IMA) (Spencer et al., 2005; Thienpont et al., 2007) and more recently liquid chromatography-tandem mass spectrometry (LC-MS/MS) methodologies (Dufour, 2007; Kahric-Janicic et al., 2007) which have progressively improved the specificity, reproducibility and sensitivity of thyroid testing methods (Thienpont et al., 2005). 
Thyroid function test has been the most popular test to diagnose an overactive or underactive thyroid gland (hyperthyroidism or hypothyroidism), monitoring response to thyroid therapy (Dayan, 2001; Midgley, 2001; Jostel et al., 2009). In this realm Ingwersen et al. (1992) eliminated the protein ANP-270 using RIA and ELISA in which the half-life of elimination was found to be 123 and 6 minutes respectively, these discrepancies were shown to be due to fragments of ANP-270 cross-reacting in the RIA but not in the ELISA. Such tests could be carried out either by RIA or ELISA; therefore the main objective of this study is to evaluate the ELISA and RIA tests for thyroid hormone levels, taking RIA as reference method.

Although enzyme immunoassay method (EIA) and ELISA with a nonradioactive procedure, less cumbersome have brought considerable benefits in terms of analytical, operational, and clinical outcomes (Wisdom, 1976; Sachidhanandam et al., 2010) and the statistically variation between the results of RIA and EIA/ELISA (Amballi et al., 2007) which has been ascribed to the effects of biological variation and factors affecting procedural analytic variation (Hackney and Viru, 2008), however RIA could surpass these techniques which are computerized dependent and case sensitive as RIA has direct bond with the serum to be measured as a hypothesized.

\section{Methodology}

The sample of this study consists of 114 patients (93 female and 21 male). The sample includes different tribes, age and gender. The blood samples $(3-5 \mathrm{ml})$ were collected from each patient, then centrifuge (3000-5000 revolution per minutes) unit over 3 minute at military hospital where ELISA has been adopted as thyroid hormones assay method using Elecsys instrument (manufactured by HITACHE-ROCHE at 2010) after evaluation, ELISA results were obtained and the sample in a serum form was send to radiation and isotope centre (RICK) at temperature $\left(18-25^{\circ} \mathrm{C}\right)$ for assay using RIA method through gamma counter instrument (manufactured by OAKFIED Company, England at 1992).

The investigation was done in the period from July 2011 to October 2011. The main equipment and reagents used in RIA included: adjustable micropipettes (10-200 $\mu 1)$, disposable polystyrene test tubes, vortex mixer (single and multitubes), multidose micropipette (Eppendorff) $25 \mu 1$ and 250 $\mu 1$, magnetic base, incubator, centrifuge, and gamma counter connected with computer.

\section{RIA technique (Thyroid hormones assay)}

Almost thyroid hormone test have the same protocol specifically T3 and T4 in this study 114 (polystyrene) test tubes were labeled in duplicates and arranged in assay rack, and then $25 \mu \mathrm{l}$ was pipette into each tube of the standards, quality control sample and patient's sample. The tracer and antibody were added in case of T3 $(100 \mu \mathrm{l})$ and $(250 \mu \mathrm{l})$ in case of $\mathrm{T} 4$ and mixed well. After mixing well incubated at $37^{\circ} \mathrm{C}$ for 45 minutes, then the rack was placed in the magnetic base for 10 minutes, to separate the bound fraction free from the free fractions by decant the supernatant. Lastly each tube was counted in the gamma counter to evaluate the gamma emission per minutes, and binding percent was plotted vs. the concentration, to get standard calibration curve, and from the curve obtained the concentration of thyroxin in the patient's samples was evaluated. The standards tube and quality control tube were measured with any group of sample patient to expose all samples to the same climate to give more accurate result.

TSH is different from T3 and T4 because it is non-competitive method in this test the 114 test tubes were labeled and arranged in assay rack in duplicates, $100 \mu 1$ of standard tubes, quality control (QC) and sample was pipette in target tube and $25 \mu 1$ tracer was added to each tube and vortexed, then incubated at $37{ }^{\circ} \mathrm{C}$ in the incubator for one hour 250 $\mu 1$ of anti TSH was added to each tube and mixed well and incubated at $25^{\circ} \mathrm{C}$ for one hour then the racks were placed in the magnetic bases for 10 minutes and the supernatant was separated by decantation. This step is followed by wash step, in this step first the concentrated wash buffer was diluted and then $500 \mu \mathrm{l}$ of the diluents was added to each tube and vortexed well and then placed again in the magnetic base, this step was repeated again and all the tubes were counted in the gamma counter.

\section{ELISA technique}

Also T3, T4 ELISA has the same principle of work. In this study a sufficient amount of patient serum and a certain amount of mouse monoclonal antibody and a constant amount of thyroid hormone conjugated (according to type of test) with horseradish peroxidase were added to the solid phase on microtitre plate. During incubation period (60 min at room temperature) the mouse antibody is bound to the second antibody on the plate. Then they are competing for the limited binding sites on the anti hormone antibody. After that the plates were washed five times by water to remove unbound hormone conjugate and then tetramethylbenzidine (TMB) solution was added and incubated for 20 minutes resulting in development of blue color. The color development is stopped with addition of stopped solution $(1 \mathrm{~N} \mathrm{HCl})$ and the absorbance was measured by spectrophotometer at $450 \mathrm{~nm}$. The concentration of hormone in the unknown sample is then calculated.

In case of TSH, 114 samples, calibrators and controls were assayed in duplicate and $50 \mu$ l of each them were pipette into correspondingly labeled plates in duplicate and then $100 \mu \mathrm{l}$ of the conjugate working solution were added into each plate. After that incubated on a plate shaker for $60 \mathrm{~min}$ utes at room temperature. Then the plates were washed three times with $300 \mu$ l of diluted wash buffer per plate and tap the plate firmly against absorbent paper to ensure that it is dry. $150 \mu \mathrm{l}$ of TMB substrate were pipette into each plate at timed intervals. Also incubate on a plate shaker for 10-15 minutes at room temperature (or until calibrator $\mathrm{F}$ attains dark blue color for desired OD), then pipette $50 \mu \mathrm{l}$ of stopping solution into each plate at the same timed intervals finally the plate on a microwell plate reader was read at $450 \mathrm{~nm}$ within 20 minutes after addition of the stopping solution. 


\section{Results}

\begin{tabular}{lcccc}
\multirow{2}{*}{$\begin{array}{l}\text { Table 1. Cross tabulation between RIA and ELISA assay result } \\
\text { of T3 }\end{array}$} & \multicolumn{3}{c}{ T3 (ELISA) } & Total \\
\cline { 2 - 4 } T3 (RIA) & Normal & Hypo & Hyper & \\
\hline Normal & 98 & 0 & 0 & 98 \\
Hypo & 0 & 4 & 0 & 4 \\
Hyper & 1 & 0 & 11 & 12 \\
Total & 99 & 4 & 11 & 114 \\
\hline
\end{tabular}

Table 2. Cross tabulation between RIA and ELISA assay result of T4

\begin{tabular}{lcccc}
\multirow{2}{*}{ T4 (RIA) } & \multicolumn{3}{c}{ T4 (ELISA) } & Total \\
\cline { 2 - 4 } & Normal & Hypo & Hyper & \\
\hline Normal & 76 & 6 & 3 & 85 \\
Hypo & 2 & 4 & 0 & 6 \\
Hyper & 3 & 1 & 19 & 23 \\
Total & 81 & 11 & 22 & 114 \\
\hline
\end{tabular}

Table 3. Cross tabulation table between RIA and ELISA assay result of TSH

\begin{tabular}{lcccc} 
& \multicolumn{3}{c}{ T4SH (ELISA) } & \multirow{2}{*}{ Total } \\
\cline { 2 - 4 } TSH RIA) & Normal & Hypo & Hyper & \\
\hline Normal & 77 & 4 & 4 & 85 \\
Hypo & 4 & 14 & 0 & 18 \\
Hyper & 4 & 0 & 7 & 11 \\
\hline
\end{tabular}

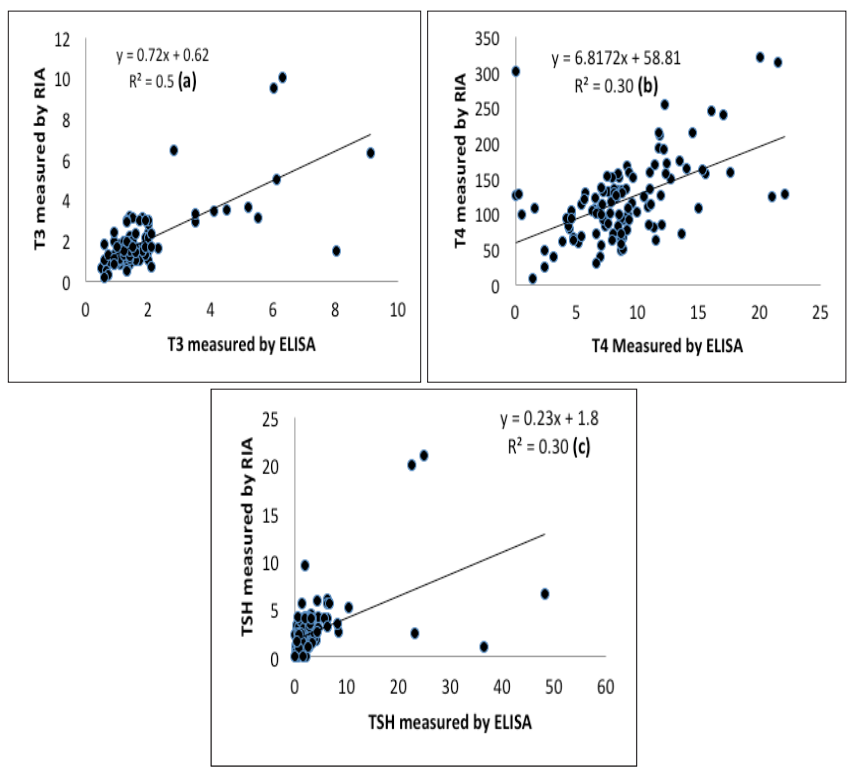

Fig. 1. Scatter plot show a linear relationship between thyroid hormones assay results using RIA method\& ELISA methods;

(a) T3, (b) T4 and (c) TSH

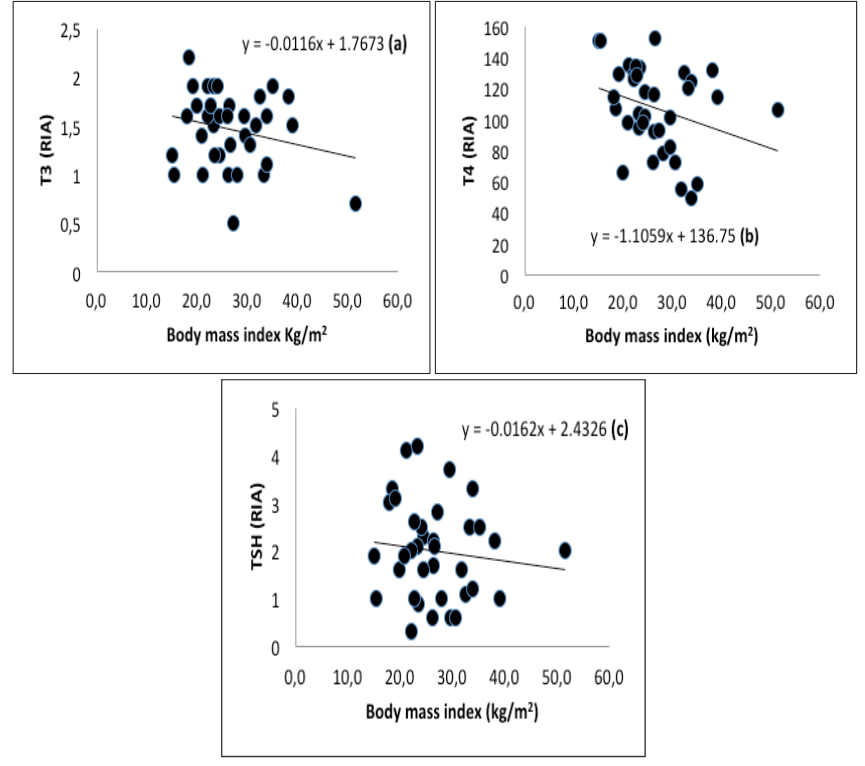

Fig. 2. Scatter plot show an inverse linear relationship of BMI and thyroid hormones assay result using RIA method; (a) T3, (b) T4 and (c) TSH

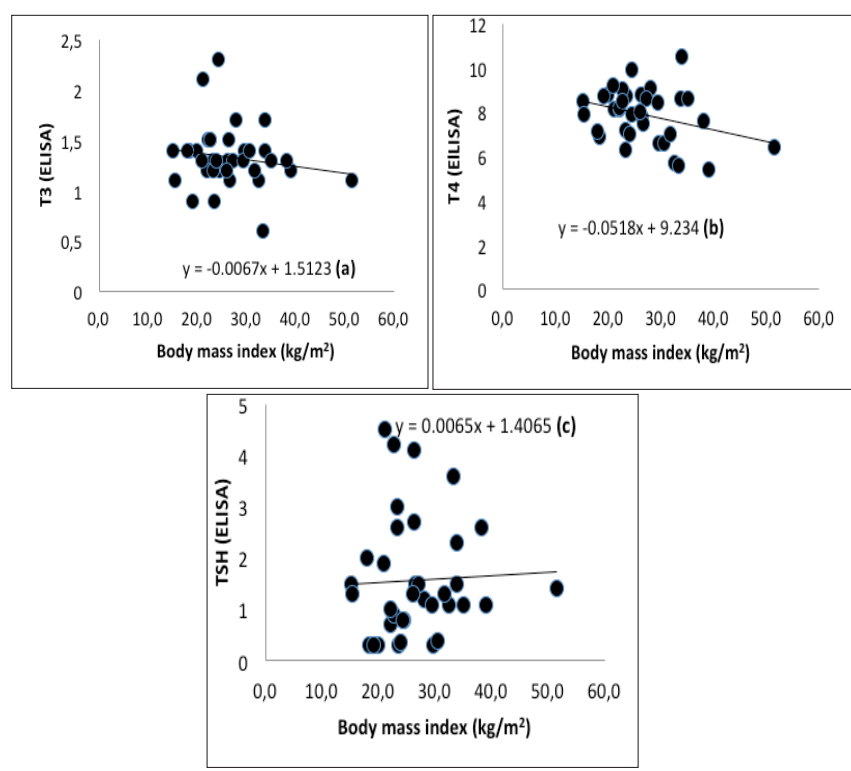

Fig. 3. Scatter plot show linear relationship of BMI and thyroid hormones assay using ELISA method; (a) T3, (b) T4 and (c) TSH

\section{Analysis and discussion}

The result of RIA has been considered as reference; therefore, T3-RIA results showed that 98 samples as normal and 16 as abnormal thyroid function (Table 1). Accordingly ELISA showed sensitivity, specificity and accuracy of $93.8 \%, 100 \%$ and $99.1 \%$ respectively. This result dictates that ELISA system got the same accuracy in respect to T3 assay. Concerning T4-RIA results as in Table 2, 85 samples were normal and 29 had abnormal and accordingly ELISA showed sensitivity, specificity and accuracy of $79.3 \%, 89.4 \%$ and $86.8 \%$ respectively. This result indicates that ELISA has lower sensitivity and relatively fair specificity and accuracy. TSH-RIA results showed that 85 samples were normal and 29 were abnormal function similar to T4 result (Table 3). This result reveals sensitivity, specificity and accuracy of $72.4 \%, 90.6 \%$ and $86 \%$ 
also this result dictate same essence as T4, where the specificity and accuracy showed relative fair result but the sensitivity showed a controversial result, such results are in agreement with Stya et al, (1984) and Gary and James, (1999). Also the result showed a good correlation between the RIA and ELISA with a direct linear relationship where ELISER result can be converted to RIA using the following coefficient $0.72,6.8$ and 0.23 for T3, T4 and TSH respectively see Figure 1. Figure 2 depict an inverse linear relationship between the BMI and T3, T4 as well as TSH using RIA whereas the amount of T3, $\mathrm{T} 4$ and TSH decreases by $0.011 \mathrm{nmol} / \mathrm{kg} / \mathrm{m}^{2}$ and $1.105 \mathrm{nmol} /$ $\mathrm{kg} / \mathrm{m}^{2}$ and $0.02 \mathrm{nmol} / \mathrm{kg} / \mathrm{m}^{2}$ respectively. This means the increase of BMI mostly lead to decrease level of T3, T4 and $\mathrm{TSH}$, this result dictate that hypothyroidism is mostly associated with obesity, which goes with the general trend as has been mentioned by Resta et al, (2004); in which they found that the prevalence of hypothyroidism was higher than that was commonly reported for patients who suffered from sleep disordered breathing and were either obese or overweight. Also Brunilda et al, (2008) have examined the effect of age and BMI on TSH levels by using a multiple linear regression analysis, they found that there is statistically significant relationship at $(\mathrm{R} 2=0.055)$, which suggests that as age and BMI increased, TSH levels also increased.

Similarly figure 3 portrayed inverse linear relationship between the BMI and T3 and T4 using ELISA whereas the amount of T3 and T4 decreases by $0.006 \mathrm{nmol} / \mathrm{kg} / \mathrm{m}^{2}$ and $0.051 \mathrm{nmol} / \mathrm{kg} / \mathrm{m}^{2}$ respectively. But TSH shows a direct linear relationship with BMI where TSH slightly increased by $0.007 \mathrm{nmol} / \mathrm{kg} / \mathrm{m}^{2}$. Also this result resembles the fashion of RIA except for TSH where the increases were significantly low.

\section{Conclusion}

The sensitivity of ELISA system over three tests relative to RIA showed unsatisfactory results, which mostly attributed to quality control inadequacy, where small shift in concentration can lead to a wrong reading, while in case of specificity and accuracy a few adjustment can lead to an identical result by using a correction factor in addition to, it requires skilled laboratory technologists and specialized laboratory equipment moreover the measurement of enzyme activity is more complex than measurement of activity of some type of radioisotopes, the enzyme activity could be affected by plasma constituents and the Kits are expensive, and the antigen won't recognize any other antigen i.e. false positives/negatives ratio, especially with mutated/altered antigen (Viswanth, 2013), therefore RIA could be considered as standard and more convenient than ELISA.

\section{REFERENCES}

Amballi, A.A., Dada, O.A., Adeleye, A.O., Salu, J., 2007. Evaluation of the determination of reference ranges for reproductive hormones (prolactin, FSH, LH, and testosterone) using enzyme immune assay method. Sci Res Essays. 2, 135-138.

Baloch, Z., Carayon, P., Conte-Devolx, B., Demers, L.M., Feldt-Rasmussen, U., Henry, J.F., LiVosli, V.A., Niccoli-Sire, P., John, R., Ruf, J., Smyth, P.P., Spencer, C.A., Stockigt, J.R., 2003. Laboratory medicine practice guidelines: Laboratory support for the diagnosis and monitoring of thyroid disease. Thyroid. 13, 57-67.

Benotti, J., Benotti, N., 1963. Protein-bound iodine, total iodine and butanol extractable iodine by partial automation. Clin. Chem, 9, 408-416.

Brunilda Figueroa, Himilce Velez,Margarita Irizarry-Ramirez., 2008. Association of thyroid-stimulating hormone levels and body mass index in Overweight Hispanics in Puerto Rico. Ethn Dis, Vol. 18, 151-154.

Figueroa, B., Velez, H , Irizarry-Ramirez, M., 2008. Association of thyroid-stimulating hormone levels and body mass index in Overweight Hispanics in Puerto Rico. Ethn Dis, 18, 151-154.

Dayan, C. M., 2001. Interpretation of thyroid function tests. The Lancet. 357, 619-624.

Dufour, D.R., 2007. Laboratory tests of thyroid function: Uses and limitations. Endocr. Metab. Clin. North Am. 36, 155-169.

Gary, C., Althouse, James E. Hixon. 1999. Use of commercially available ELISAs to help determine estrous status in female swine. Swine Health and Prod. 7, 65-68.

Hackney, A.C., Viru, A., 2008. Research methodology: Endocrinologic measurements in exercise science and sports medicine. J. Athl. Train. 43,631-639.

Hoermann, R., Eckl, W., Hoermann, C., Larisch, R., 2010. Complex relationship between free thyroxine and TSH in the regulation of thyroid function. Eur J Endocrinol. 162, 1123-1129.

Ingwersen, S.H., Jørgensen, P.N., Eiskjaer, H., Johansen, N.L., Madsen, K., Faarup, P., 1992. Superiority of sandwich ELISA over competitive RIA for the estimation of ANP-270, an analogue of human atrial natriuretic factor. J Immunol Methods. 149, $237-246$.

Jostel, A., Ryder, W.D., Shalet, S. M., 2009. The use of thyroid function tests in the diagnosis of hypopituitarism: Definition and evaluation of the TSH Index. Clin. Endocrinol. 71, 529-534.

Kahric-Janicic, N., Soldin, S.J, Soldin, O.P., West, T.G.J., Jonklaas, J., 2007. Tandem mass spectrometry improves the accuracy of free thyroxine measurements during pregnancy. Thyroid. 17, 303-311.

Midgley, J. E. M., 2001. Direct and indirect free thyroxin assay methods: Theory and practice. Clin. Chem. 47, 1353-1363.

Resta, O., Pannacciulli, N., Di Gioia, G., Stefano, A., Barbaro, M.P., De Pergola, G., 2004. High prevalence of previously unknown subclinicalhypothyroidism in obese patients referred to a sleep clinic for sleep disordered breathing. Nutr. Metab. Cardiovasc. Dis. 14, 248253.

Roberts, R.F., Laulu, S.L., Roberts, W.L., 2007. Performance characteristics of seven automated thyroxine and T-uptake method. Clin. Chim. Acta. 377, 248-255.

Sachidhanandam, M., Singh, S. N., Salhan, A. K.,. Ray, U.S., 2010. Evaluation of plasma hormone concentrations using enzyme immunoassay/ enzyme-linked immunosorbent assay in healthy Indian men: Effect of ethnicity. Indian J Clin Biochem. 25, 153-157.

Sanchez-Carbayo, M., Mauri, M., ALfayate, R., Miralles, C., Soria, F., 1994. Analythical evaluation of TSH \& thyroid hormones by electrochemiluminescent immunoassay. Clin. Biochemistry. 32, 395-403.

Spencer, C.A., Bergoglio, L.M., Kazarosyan, M., Fatemi, S., LoPresti, J.S., 2005. Clinical impact of thyroglobulin (Tg) and Tg autoantibody method differences on the management of patients with differentiated thyroid carcinomas. J. Clin. Endocrinol. Metab. 90, 5566-5575.

Stya, M., Wahl, R.,. Beierwaltes, W.H., 1984. Dot-Based ELISA and RIA” Two Rapid Assays that screen hybridoma supernatants against whole 
live cells. J Immunol Methods. 73, 75-81.

Thienpont, L.M., Beastall, G., Christofides, N.D., Faix, J.D., Ieiri, T., Jarrige, V., Miller, W.G., Miller, R., Nelson, J.C., Ronin, C., Ross, H.A., Rottmann, M., Thijssen, J.H., Toussaint, B., 2007. Proposal of a candidate international conventional reference measurement procedure for free thyroxine in serum. Clin. Chem. Lab. Med. 45, 934-936.

Thienpont, L.M., Van Uytfanghe, K., Marriott, J., Stokes, P., Siekmann, L., Kessler, A., Bunk, D., Tai, S., 2005. Feasibility study of the use of frozen human sera in split-sample comparison of immunoassays with candidate reference measurement procedures for total thyroxine and total triiodothyronine measurements. Clin. Chem. 51, 2303-2311.

Van Herle, A.J., Pick, P., Ljung, B.M.E., Ashcraft, M.W., Solomon, D.H., Keeler, E.B., 1982. The thyroid nodule. Ann. Intern. Med. 96, $221-232$.

Viswanth, S., Reddym, ? 2013. Presentation about ELISA \& RIA (pharmacology) Gokaraju Rangaraju college of pharmacy-1. (http://www. slideshare.net/vishwanth555/elisa-ria - 27\11 (2013).

Wisdom, G. B., 1976. Enzyme-immunoassay. Clin. Chem. 22, 1243-1255. 